\title{
Thrombotic microangiopathy associated with use of interferon-beta
}

Teresa Olea'

Raquel Díaz-Mancebo'

Maria-Luz Picazo ${ }^{2}$

Jorge Martínez-Ara'

Angel Robles ${ }^{3}$

Rafael Selgas'

'Departments of Nephrology, ${ }^{2}$ Pathology, ${ }^{3}$ Internal Medicine, Hospital Universitario La Paz, Madrid, Spain
Correspondence: Teresa Olea Nephrology Department, Hospital Universitario La Paz, Paseo de la Castellana, 26I, Madrid 28046, Spain

$\mathrm{Tel}+349$ 1727 7/5!

Email tolea.hulp@salud.madrid.org
This article was published in the following Dove Press journal: International Journal of Nephrology and Renovascular Disease 14 June 2012

Number of times this article has been viewed

\begin{abstract}
Interferon-beta is widely used for the treatment of relapsing multiple sclerosis. The drug is usually well tolerated, but autoimmune adverse effects, including kidney disease, have been reported. Only a few cases of hemolytic uremic syndrome-thrombotic microangiopathy associated interferon-alpha have been described so far, and even fewer with beta-interferon. We report a patient who developed thrombotic microangiopathy during treatment with interferon-beta and improved after discontinuation and steroid therapy. Complement cascade and antiphospholipid antibodies are investigated. The spectrum of renal diseases associated with interferon-beta treatment is also reviewed.
\end{abstract}

Keywords: thrombotic microangiopathy hemolytic uremic syndrome, multiple sclerosis, interferon-beta

\section{Introduction}

Interferons are well established agents for standard therapy in several malignancies, hepatitis $\mathrm{C}$, idiopathic pulmonary fibrosis, and multiple sclerosis. ${ }^{1,2}$ Despite this, adverse autoimmune effects associated with their use have been reported, including minimal change disease in the kidney, ${ }^{2-5}$ collapsing focal segmental glomerulosclerosis, ${ }^{6,7}$ membranous glomerulonephritis, ${ }^{8}$ acute renal failure, ${ }^{9}$ lupus nephritis, ${ }^{10,11}$ acute renal failure, ${ }^{12}$ and thrombotic microangiopathy. ${ }^{13-18}$ These side effects are most often associated with interferon-alpha therapy, rather than interferon-beta. The mechanism for this is not clear. Glomerular endothelial cells express and secrete ADAMTS $13 .{ }^{17}$ The low activity of ADAMTS 13 has been associated with the presence of an antiADAMTS 13 IgG antibody during treatment with interferon-alpha $2 \mathrm{a},{ }^{16}$ which could explain these adverse side effects, but no mechanism has been described to explain this with interferon-beta. In the following report, we describe a case of hemolytic uremic syndrome causing thrombotic microangiopathy and chorioretinitis after several months on treatment with interferon-beta which is much rarer. It responded successfully to drug withdrawal and steroid therapy.

\section{Case report}

A 37-year-old woman was admitted to our hospital with acute renal failure, hypertension, subnephrotic proteinuria, nausea, and vomiting. She reported a 20 -year history of multiple sclerosis, adequately controlled with steroids. She had been treated with interferon-beta due to a sensitive relapse affecting the spinal cord and both legs during the last five months. The patient refused other medications. She had no recent history 
of fever or diarrhea. She reported a two-week history of mild fatigue and arthralgia in the left tarsus, treated with ibuprofen. On admission, the patient had a blood pressure of 205/110 mmHg. She was well hydrated and, apart from pedal edema, physical examination was unremarkable. No skin lesions were detected.

Laboratory test results are shown in Table 1. A possible diagnosis of acute renal injury secondary to thrombotic microangiopathy associated with interferon-beta was suggested. Urinalysis showed no leucocytes, erythrocytes, or nitrites. Proteins were $1.7 \mathrm{~g} / 24$ hours. Urine culture showed no pathogens.

Cancer markers were negative. Chest x-ray was unremarkable and renal ultrasound showed kidneys of normal size with a normal echogenic cortex and no hydronephrosis. A kidney biopsy was performed and histological studies showed ischemic changes in 12 of 35 glomeruli studied (Figure 1A). Some other glomeruli showed chronic glomerular microangiopathic lesions with duplication of the glomerular basement membrane (Figure 1B). There was moderate interstitial edema with mild inflammatory cell infiltration and patchy tubular atrophy. The arterioles and intralobular arteries showed marked subintimal fibromucoid edema narrowing the lumen (Figure 1A arrows, Figure 2A). An immunofluorescence study showed only fibrinogen deposits in the arterial wall (Figure 2B).

The patient was finally diagnosed with thrombotic microangiopathy associated with interferon-beta, so the drug was withdrawn and immunosuppressive therapy was started with $1 \mathrm{mg} / \mathrm{kg} /$ day of prednisone because leg symptoms of

Table I Results of laboratory investigations

\begin{tabular}{|c|c|c|c|}
\hline & $\begin{array}{l}\text { May 2I, } \\
2008\end{array}$ & $\begin{array}{l}\text { June I3, } \\
2008\end{array}$ & $\begin{array}{l}\text { August 8, } \\
2008\end{array}$ \\
\hline Creatinine (mg/dL ) & 2.4 & 1.0 & 0.8 \\
\hline Urea $(\mathrm{mg} / \mathrm{dL})$ & 86 & 42 & 24 \\
\hline Proteinuria (g/24 hours) & 1.7 & 0.28 & 0.03 \\
\hline Hemoglobin (g/dL) & 9.3 & 10.3 & II.2 \\
\hline Platelets $\left(\mathrm{mm}^{3}\right)$ & 108,000 & 229,000 & 265,000 \\
\hline $\begin{array}{l}\text { Lactate dehydrogenase } \\
\text { (IU/L) }\end{array}$ & 491 & 348 & 257 \\
\hline Schistocytes & Positive & Negative & Negative \\
\hline ANCA & Negative & Negative & Negative \\
\hline ANA & Negative & Negative & Negative \\
\hline Anti DNA & Negative & Negative & Negative \\
\hline Anti Ro & Negative & Negative & Negative \\
\hline Anti La & Negative & Negative & Negative \\
\hline Factor $\mathrm{H}, \mathrm{I}$ & Normal range & - & - \\
\hline Antiphospholipid (*) & Negative & Negative & Negative \\
\hline
\end{tabular}

Note: *Antiphospholipids included anticardiolipin, lupus anticoagulant and anti $\beta 2 \mathrm{GPI}$. Abbreviations: ANA, antinuclear antibodies; ANCA, antineutrophil cytoplasmic antibodies.

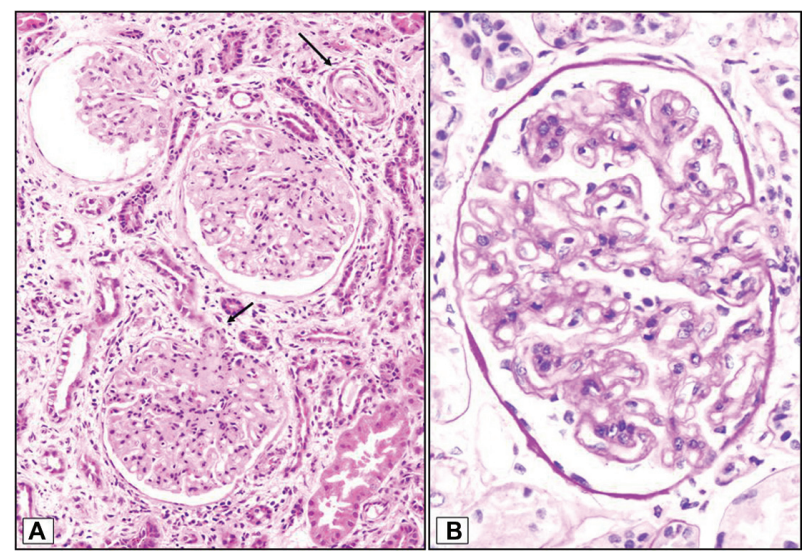

Figure I (A) Ischemic changes in the upper glomeruli (arrow). Marked subintimal fibromucoid edema narrowing the lumen in the intralobular arterioles (arrows) and (B) duplication of glomerular basement membrane.

multiple sclerosis had started immediately. Doses of steroids were reduced and finally withdrawn over a period of one month, while glatiramer acetate was started. The leg symptoms of multiple sclerosis disappeared in a few days. Her hypertension was controlled with enalapril and irbesartan. Hematological abnormalities and serum lactate dehydrogenase levels returned to the normal range, and renal function slowly recovered a serum creatinine of $1.0 \mathrm{mg} / \mathrm{dL}$.

\section{Discussion}

Interferon-beta is widely used for the treatment of relapsing multiple sclerosis. It is postulated that interferon-beta acts in this disease by inhibiting activation and proliferation of T cells. ${ }^{1,2}$ The drug is usually well tolerated, but constitutional side effects and autoimmune adverse events have been reported. ${ }^{19,20}$

The similarities between some manifestations of systemic lupus erythematosus, those of viral infections, and side effects of immunotherapy with recombinant interferons,

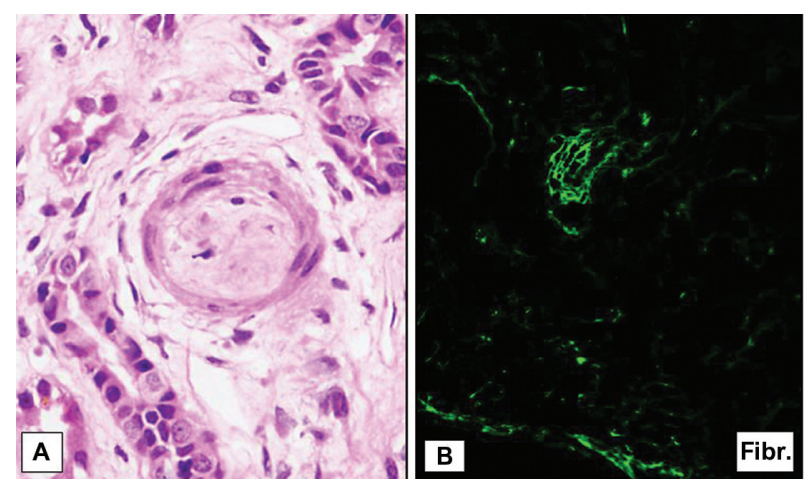

Figure 2 (A) Moderate interstitial edema with mild inflammatory cell infiltration and patched tubular atrophy with (B) fibrinogen deposits in the arterial wall in the immunofluorescence study. 
Table 2 Spectrum of renal diseases induced by interferon-beta

\begin{tabular}{|c|c|c|c|c|c|c|c|c|}
\hline Authors & Year & Gender & Age & Disease & Clinical & Kidney biopsy & Treatment & Evolution \\
\hline Ubara et $\mathrm{a}^{22}$ & 1998 & Female & 66 & $\mathrm{CHC}$ & HUS & Thrombotic microangiopathy & SB & $\begin{array}{l}\text { Remission } \\
\text { HUS }\end{array}$ \\
\hline Gostman et $\mathrm{al}^{6}$ & 2000 & Female & 52 & MS & NS & $\begin{array}{l}\text { Focal segmental } \\
\text { glomerulosclerosis }\end{array}$ & SB & Remission NS \\
\hline Nakao et $\mathrm{l}^{5}$ & 2002 & Male & 64 & Melanoma & NS & Minimal change disease & SB & Remission NS \\
\hline Tola et $\mathrm{a}^{4}$ & 2003 & Male & 39 & MS & NS & Minimal change disease & $\begin{array}{l}\text { SB - Steroids - } \\
\text { azathioprine }\end{array}$ & Remission NS \\
\hline Auty and Saleh ${ }^{9}$ & 2005 & Male & 28 & MS & NS & Membranous nephropathy & $\begin{array}{l}\text { SB - Steroids } \\
\text { CsA - MMF }\end{array}$ & Remission NS \\
\hline Kamasaka et $\mathrm{al}^{3}$ & 2006 & Female & 43 & MS & NS & Minimal change disease & SB - Steroids & Remission NS \\
\hline Hansen et al" & 2009 & Male & 41 & MS & RF & $\begin{array}{l}\text { Thrombotic microangiopathy, } \\
\text { antiphospholipid, SLE }\end{array}$ & $\begin{array}{l}\text { SB - Steroids - } \\
\text { CFM - MMF }\end{array}$ & CKD \\
\hline Aravindan et $\mathrm{al}^{2}$ & 2010 & Female & 44 & MS & NS & Minimal change disease & SB - Steroids - ACEI & Remission NS \\
\hline Markowitz et $\mathrm{al}^{7}$ & 2010 & Female & 27 & MS & NS & Collapsing focal segmental & NA & NA \\
\hline & & Female & 33 & MS & RF-Prot & SLE and Glomerulosclerosis & SB - Steroids & CKD \\
\hline & & Female & 37 & MS & RF-Prot & & SB - Steroids - CFM & Proteinuria \\
\hline Broughton et $\mathrm{al}^{21}$ & 2011 & Female & 53 & MS & $\begin{array}{l}\text { RF-Prot } \\
\text { Mhem }\end{array}$ & Thrombotic microangiopathy & SB - ACEI & $\begin{array}{l}\text { CKD } \\
\text { Mhem }\end{array}$ \\
\hline
\end{tabular}

Abbreviations: CHC, chronic hepatitis C; HUS, hemolytic uremic syndrome; MS, multiple sclerosis; NS, nephrotic syndrome; SB, stopped interferon-beta; CsA, cyclosporin; MMF, mycophenolate mofetil; RF, renal failure; NA, not available; CKD, chronic kidney disease; Prot, proteinuria; Mhem, microhematuria; CFM, cyclophosphamide; $A C E I$, angiotensin-converting enzyme inhibitors; SLE, systemic lupus erythematosus.

such as fever, arthralgia, myalgia, and fatigue, are evident. In fact, interferon-alpha is a central mediator in systemic lupus erythematosus, and specific neutralizing antibodies are now in clinical trials for the treatment of this disease. ${ }^{21}$ Our case can be immediately catalogued as a thrombotic microangiopathy-hemolytic uremic syndrome, which would explain the acute kidney injury. The absence of diarrhea made atypical hemolytic uremic syndrome very unlikely. She had no symptoms or serological findings suggestive of systemic sclerosis, malignancy, malignant hypertension, or antiphospholipid syndrome. The presence of autoreactive antibodies, particularly antiphospholipid antibodies and antithyroid antibodies, are associated with an increased risk of interferon-beta antibodies in patients with multiple sclerosis on long-term therapy. ${ }^{22}$ However, we did not find any of these antibodies in our patient. Kidney complications have not been directly attributed to multiple sclerosis. ${ }^{2}$

Renal side effects including minimal change disease, ${ }^{2-5}$ collapsing focal segmental glomerulosclerosis, ${ }^{6-8}$ membranous nephropathy, ${ }^{9}$ lupus nephritis, ${ }^{10,11}$ acute renal failure, ${ }^{12}$ and thrombotic microangiopathy, ${ }^{13-23}$ are most often associated with interferon therapy rather than with interferon-beta. The incidence of transient proteinuria during interferon-beta therapy is around $20 \%$. To our knowledge, this is the fourth case of hemolytic uremic syndrome induced by interferonbeta. Two of these patients were treated with corticosteroids and plasmapheresis, and another was only treated with supportive antihypertensive and antiproteinuric therapies.
The fourth patient was diagnosed also with pseudo-SLE and treated with immunosuppressants. In all of them interferonbeta was withdrawn. The spectrum of kidney disease related to interferon-beta is shown in Table 2.

The mechanism by which interferon could induce thrombotic microangiopathy lesions and nephrotic syndrome remains unclear. ${ }^{14}$ Pleiotropic drugs such as interferon might disrupt complex pathways of complement regulation and play a role in endothelial damage. ${ }^{21}$ In recent years, mutation of complement system regulators (factors $\mathrm{H}$ and $\mathrm{I}$, and membrane cofactor protein) have been directly implicated in the induction of atypical hemolytic uremic syndrome. ${ }^{24,25}$ However, we did not found any of these alterations in our case. Furthermore, a recent publication described a case of low ADAMTS 13 activity associated with the presence of an anti-ADAMTS 13 IgG antibody during treatment with interferon-alpha $2 \mathrm{a} .{ }^{16}$ Glomerular endothelial cells express and secrete ADAMTS $13 .{ }^{17}$ It has been suggested that pre-eclampsia is also associated with decreased levels of ADAMTS $13 .{ }^{18}$

The delayed appearance of thrombotic microangiopathy observed in our case and others suggest that the development of renal lesions may be the result of cumulative effects. ${ }^{14,22}$ In conclusion, thrombotic microangiopathy-hemolytic uremic syndrome induced by interferon-beta is an unusual side effect manifested as acute or subacute kidney injury. Attempts should be made to detect it as soon as possible, and to clarify the mechanism of microangiopathy lesions. 


\section{Disclosure}

The authors report no conflicts of interest in this work.

\section{References}

1. Walther EU, Hohlfeld R. Multiple sclerosis: side effects of interferon beta therapy and their management. Neurology. 1999;53:1622-1627.

2. Aravindan A, Yong J, Killingsworth M, Suranyi M, Wong J. Minimal change disease with interferon-beta therapy for relapsing remitting multiple sclerosis. NDT Plus. 2010;3:132-134.

3. Kamasaka R, Nakamura N, Shirato K, et al. Nephrotic syndrome associated with interferon beta-1b therapy for multiple sclerosis. Clin Exp Nephrol. 2006;10:222-225.

4. Tola MR, Caniatti LM, Gragnaniello D, et al. Recurrent nephrotic syndrome in patient with multiple sclerosis treated with interferon beta 1a. J Neurol. 2003;250:768-769.

5. Nakao K, Sugiyama H, Makino E, et al. Minimal change nephrotic syndrome developing during postoperative interferon-beta therapy for malignant melanoma. Nephron. 2002;90:498-500.

6. Gotsman I, Elhalel-Darnitski M, Friedlander Z, et al. Beta-interferoninduced nephrotic syndrome in a patient with multiple sclerosis. Clin Nephrol. 2000;54:425-426.

7. Markowitz GS, Nasr SH, Stokes MB, D'Agati VD. Treatment with INF- $\alpha,-\beta$ or $-\gamma$ is associated with collapsing focal segmental glomerulosclerosis. Clin J Am Soc Nephrol. 2010;5:607-615.

8. Bremer CT, Lastrapes A, Alper AB Jr, et al. Interferon-alpha-induced focal segmental glomerulosclerosis in chronic myelogenous leukemia: a case report and review of the literature. Am J Clin Oncol. 2003;26: 262-264.

9. Auty A, Saleh A. Nephrotic syndrome in a multiple sclerosis patient treated with interferon beta 1a. Can J Neurol Sci. 2005;32:366-368.

10. Abbott IJ, Chang CC, Skinner MJ, et al. Development and management of systemic lupus erythematosus in an HIV-infected man with hepatitis $\mathrm{C}$ and B co-infection following interferon therapy: a case report. $J$ Med Case Reports. 2009;3:7289.

11. Hansen T, New D, Reeve R, Donne R, Stephens W. Acute renal failure, systemic lupus erythematosus and thrombotic microangiopathy following treatment with beta-interferon for multiple sclerosis: case report and review of the literature. NDT Plus. 2009;2:466-468.

12. Fahal IH, Murry N, Chu P, Bell GM. Acute renal failure during interferon therapy. Br Med J. 1993;306:973.
13. Jadoul M, Piessevaux H, Ferrant A, Cosyns JP, van Ypersele de Striou C. Renal thrombotic microangiopathy in patients with chronic myelogenous leukaemia treated with interferon alpha 2b. Nephrol Dial Transplant. 1995;10:111-113.

14. Badid C, McGregor B, Faivre JM, et al. Renal thrombotic microangiopathy induced by interferon $\alpha$. Nephrol Dial Transplant. 2001;16: 846-848.

15. Magee CC. Renal thrombotic microangiopathy induced by interferonalpha. Nephrol Dial Transplant. 2001;16:2111-2112.

16. Kitano K, Gibo Y, Kamijo A, et al. Thrombotic thrombocytopenic purpura associated with pegylated-interferon alpha-2a by ADAMTS 13 inhibitor in a patient with chronic hepatitis C. Haematologica. 2006;91:ERC34.

17. Tati R, Kristoffersson AC, Ståhl AL, et al. Phenotypic expression of ADAMTS 13 in glomerular endothelial cells. PLoS One. 2011;6: e21587.

18. Stepanian A, Cohen-Moatti M, Sanglier T, et al; ECLAXIR Study Group. Von Willebrand factor and ADAMTS13: a candidate couple for preeclampsia pathophysiology. Arterioscler Thromb Vasc Biol. 2011;31:1703-1709.

19. Alanoglu G, Kilbas S, Arslan C, Senol A, Kutluhan S. Autoimmune hemolytic anemia during interferon-beta- $1 \mathrm{~b}$ treatment for multiple sclerosis. Mult Scler. 2007;13:683-685.

20. Garg N, Weinstock-Guttman B, Bhasi K, Locke J, Ramanathan M. An association between autoreactive antibodies and anti-interferon-beta antibodies in multiple sclerosis. Mult Scler. 2007;13:895-899.

21. Broughton A, Cosyns JP, Jadoul M. Thrombotic microangiopathy induced by long-term interferon- $\beta$ theraphy for multiple sclerosis: a case report. Clin Nephrol. 2011;5:396-400.

22. Ubara Y, Hara S, Takedatu H, et al. Hemolytic uremic syndrome associated with beta-interferon therapy for chronic hepatitis C. Nephron. 1998;80:107-108.

23. Herrera WG, Balizet LB, Harberts SW, Brown ST. Occurrence of a TTP-like syndrome in two women receiving beta interferon therapy for relapsing multiple sclerosis. Neurology. 1999; Supp 2:A153.

24. Anders HJ, Lichnekert J, Allam R. Interferon- $\alpha$ and $-\beta$ in kidney inflammation. Kidney Int. 2010;77:848-854.

25. Noris M, Remuzzi G. Atypical hemolytic-uremic syndrome. N Engl JMed. 2009;362:1676-1679.

\section{Publish your work in this journal}

The International Journal of Nephrology and Renovascular Disease is an international, peer-reviewed open-access journal focusing on the pathophysiology of the kidney and vascular supply. Epidemiology, screening, diagnosis, and treatment interventions are covered as well as basic science, biochemical and immunological studies. The journal welcomes original research, clinical studies, reviews \& evaluations, expert opinion and commentary, case reports and extended reports. The manuscript management system is completely online and includes a very quick and fair peerreview system, which is all easy to use. Visit http://www.dovepress.com/ testimonials.php to read real quotes from published authors. 